UCRL-JC-128290

PREPRINT

\title{
The Fabrication and Testing of Optics for EUV Projection Lithography
}

\author{
J. S. Taylor, G. E. Sommargren, D. W. Sweeney, \\ R. M. Hudyma, and E. M. Gullikson
}

This paper was prepared for and presented at the

OSA 1998 Summer Topical Meetings

Kailua-Kona, HI

June 8-12, 1998

March 13, 1998

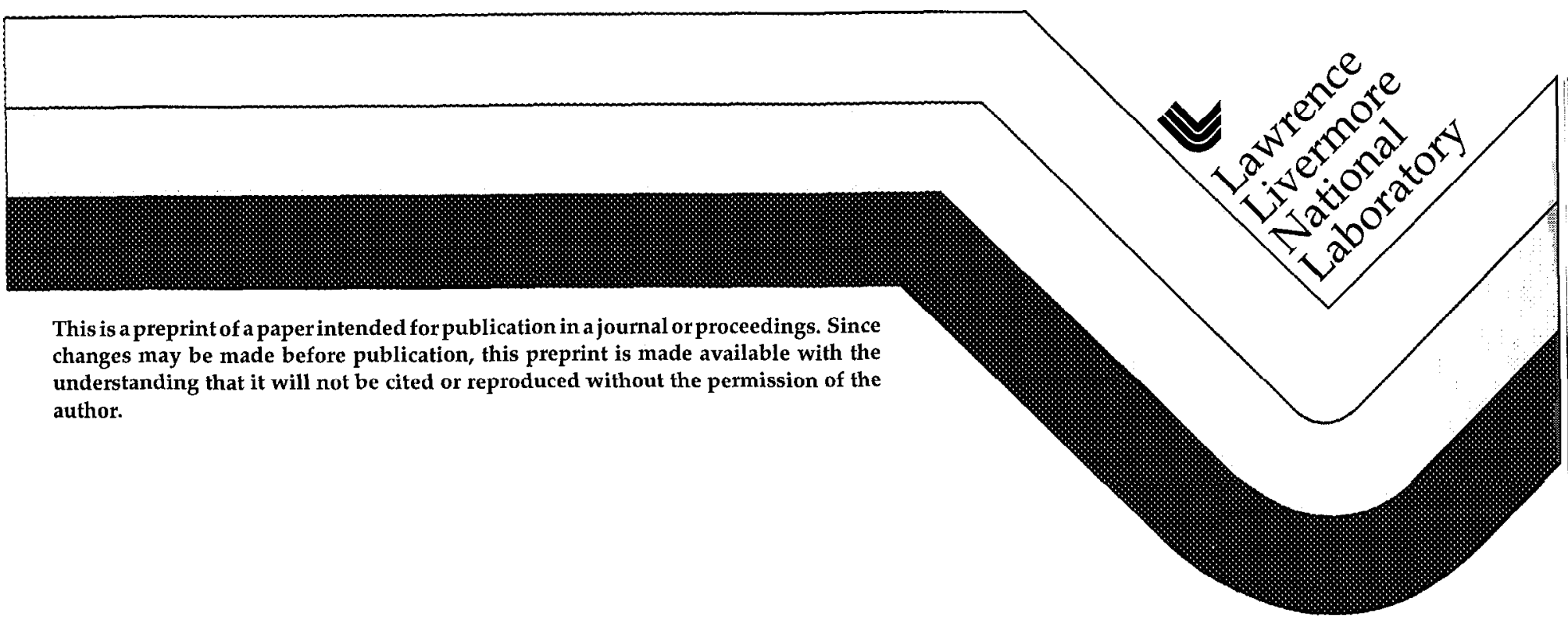




\section{DISCLAIMER}

This document was prepared as an account of work sponsored by an agency of the United States Government Neither the United States Government nor the University of California nor any of their employees, makes any warranty, express or implied, or assumes any legal liability or responsibility for the accuracy, completeness, or usefulness of any information, apparatus, product, or process disclosed, or represents that its use would not infringe privately owned rights. Reference herein to any specific commercial product, process, or service by trade name, trademark, manufacturer, or otherwise, does not necessarily constitute or imply its endorsement, recommendation, or favoring by the United States Government or the University of California The views and opinions of authors expressed herein do not necessarily state or reflect those of the United States Government or the University of California, and shall not be used for advertising or product endorsement purposes 


\title{
The Fabrication and Testing of Optics for EUV Projection Lithography, ${ }^{1,2}$
}

\author{
John S. Taylor, Gary E. Sommargren, Donald W. Sweeney, Russell M. Hudyma \\ L-395, Lawrence Livermore National Laboratory, Livermore, CA 94551 \\ Eric M. Gullikson \\ Lawrence Berkeley National Laboratory, Berkeley, CA 94720
}

\section{Introduction}

Extreme UltraViolet Lithography (EUVL) is a leading candidate as a stepper technology for fabricating the "0.1 $\mu \mathrm{m}$ generation" of microelectronic circuits. EUVL is an optical printing technique qualitatively similar to Deep UV Lithography (DUVL), except that $11-13 \mathrm{~nm}$ wavelength light is used instead of $193-248 \mathrm{~nm}$. The feasibility of creating $0.1 \mu \mathrm{m}$ features has been well-established using small-field EUVL printing tools, and development efforts are currently underway to demonstrate that cost-effective production equipment can be engineered to perform full-width ring-field imaging consistent with high wafer throughput rates. Ensuring that an industrial supplier base will be available for key components and subsystems is crucial to the success of EUVL. In particular, the projection optics are the heart of the EUVL imaging system, yet they have figure and finish specifications that are beyond the state-of-the-art in optics manufacturing. Thus it is important to demonstrate that industry will be able to fabricate and certify these optics commensurate with EUVL requirements.

The goal of this paper is to demonstrate that procuring EUVL projection optical substrates is feasible. This conclusion is based on measurements of both commercially-available and developmental substrates.

\section{Specifications}

EUVL projection systems employ all-reflective configurations in a ring field geometry with the mirror surfaces having stringent specifications on both figure and finish. Nominal specifications for the average allowable figure and finish errors on individual substrates for a 4-mirror EUVL projection optics design are given in Table 1. These multi-mirror systems typically utilize aspheric surfaces to obtain aberration reduction, which adds a significant degree of difficulty to the fabrication and testing of the substrates.

The three specification categories listed in Table 1 are tied closely to performance requirements. The figure specification is motivated by the requirement for a high resolution imaging system with low distortion across the image field. If the projection optics are to achieve diffraction-limited performance by Marechal's criterion, the composite wavefront error (at the exit pupil) must be less than $\lambda / 14 \mathrm{rms}$ where $\lambda$ is the operating wavelength $(\lambda=13.4 \mathrm{~nm})$. In the context of our 4-mirror system, each surface should contribute, on the average, no more than $0.5 \mathrm{~nm}$ rms of WFE (assuming the errors are uncorrelated), which leads to the average figure error of $0.25 \mathrm{~nm} \mathrm{rms}$ specified in Table 1. Mid-spatial frequency roughness (MSFR) (spatial periods of $1 \mathrm{~mm}$ to $1 \mu \mathrm{m}$ ) causes near-angle scattering where the scattered light remains in the image field. Thus, MSFR causes a background illumination, usually referred to as flare, that is superimposed on the desired image. The most prominent effect of flare is to

Table 1. Nominal specifications for EUVL projection optics (4 mirror system).

\begin{tabular}{|l|l|l|}
\hline Error Term & $\begin{array}{c}\text { Maximum } \\
\text { Error } \\
\text { Specification }\end{array}$ & $\begin{array}{l}\text { Defined by integrating the Power } \\
\text { Spectral Density (PSD) of surface } \\
\text { errors over the following } \\
\text { bandlimits: }\end{array}$ \\
\hline Figure & $0.25 \mathrm{~nm} \mathrm{rms}$ & $($ Clear Aperture) \\
\hline $\begin{array}{l}\text { Mid-Spatial Frequency } \\
\text { Roughness (MSFR) }\end{array}$ & $0.20 \mathrm{~nm} \mathrm{rms}$ & $1 \mathrm{~mm}^{-1}-1 \mu \mathrm{m}^{-1}$ \\
\hline $\begin{array}{l}\text { High-Spatial Frequency } \\
\text { Roughness (HSFR) }\end{array}$ & $0.10 \mathrm{~nm} \mathrm{rms}$ & $1 \mu \mathrm{m}^{-1}-50 \mu \mathrm{m}^{-1}$ \\
\hline
\end{tabular}


reduce image contrast, which adversely limits the range of acceptable operating conditions (process window) for performing lithography. In addition, if the flare is non-uniform over the image field, then the critical dimensions (CD) of printed features will also exhibit non-uniformity. Modeling efforts indicate that acceptable levels of image contrast and $C D$ variation can be achieved for MSFR levels of $0.2 \mathrm{~nm} \mathrm{rms}$, as specified in Table 1 . Wide-angle scattering is caused by high-spatial frequency roughness (HSFR) (spatial periods $<1 \mu \mathrm{m}$ ) and results in a loss to the system because light is scattered outside of the image field. Wide-angle scattering also decreases contrast by reducing the intensity of the "light" areas of the image field, in comparison with near-angle scattering, which decreases contrast by redistributing energy within the image field.

\section{The Evolution of Optical Fabrication to Meet EUVL Specifications}

Figure 1 is a plot of surface errors for the three key specification categories (figure, MSFR, HSFR) versus the year in which they should be achieved in order to meet current program requirements; each of the three lines corresponds to a different category. The three points at 1997 ("Sandia 5x") are the measured values from aspheric surfaces fabricated for another project and represent the state-of-the-art for combined figure and finish at the beginning of the current program. The fact that the MSFR is greater than the figure error is indicative of the impressive level of determinism in the figuring process, while also indicating that finish is often sacrificed during aspheric processing. In comparison, the data point labeled "CRADA" for mid-1996 represents an impressive $0.3 \mathrm{~nm}$ rms measured figure error, although finish was not specifically controlled for that optic. ${ }^{3}$ The points indicated for 1998 and 1999 are the specifications for optics required in the current effort; the "intermediate specifications" in 1998 offer an interim milestone mid-way during the finishing process development that links the state-of-the-art in 1997 with the final requirements for 1999.

The two points to the right of 1999 labeled as "Classical Superpolishing" are the levels of MSFR and HSFR that can be produced on flats and spheres by companies that perform "superpolishing", such as for laser gyro components. These points represent a "proof of existence" that demonstrates that optical fabrication methods can indeed attain these levels of finish.

There is a growing effort in the optics community to improve aspheric fabrication technolugy in order to meet the future needs of EUVL. Our program is assessing this rate of improvement by purchasing optical substrates from commercial supplier(s) using specifications that become increasingly stringent to kcep pace with the requircd rate of development as shown in Figure 1.

Our test and evaluation samples have been obtained from commercial source(s) and have all been fabricated using aspheric processing methods, although the surface contours are flat or spherical in order to simplify inspection. Some of the substrates have had simultaneous figure and finish specifications, while others have concentrated on improving finish while using aspheric methods. In all cases, the required specifications have been met.

The results for two of the developmental samples are shown in Figure 1. Sample $C$ is a spherical substrate fabricated using aspheric methods with specifications for figure, MSFR, and HSFR and provides an apples-to-apples comparison with the aspheric surfaces for the "Sandia $5 \mathrm{x}$ " measurements. The key observation is that even while maintaining figure quality to $0.6 \mathrm{~nm} \mathrm{rms}$, the values of MSFR and HSFR dropped to $0.51 \mathrm{~nm}$ rms and $0.20 \mathrm{~nm} \mathrm{rms}$, respectively. The goal of flat Sample $\mathrm{E}$ was to focus aspheric processing development on improving surface finish, without a stringent 
specification on figure. The MSFR value of $0.30 \mathrm{~nm}$ rms and HSFR value of $0.14 \mathrm{~nm}$ rms are plotted on the timeline in Figure 1. Both of these values are closely approaching the final EUVL specifications.

\section{Calculation of Surface Errors}

As noted in the definition of the specifications given in Table 1, the relevant parameter is the rms power obtained by integrating the 2-D power spectral density (PSD) over an appropriate band of spatial frequencies. The use of 1-D PSDs is well-described in the literature, particularly in relating light scattering to surface statistics. However, the calculation of statistics from the 2-D PSD is relatively uncommon, although there is a trend for its increasing application. In order to calculate the relevant surface statistics, we calculate the 2-D PSD, and then delineate a circular region within the frequency domain with a radius of the Nyquist frequency (or an ellipse if the Nyquist frequencies are different in the $x$ and $y$ directions). We then integrate the 2-D PSD in the annular region that includes the spatial frequencies that are relevant. For example, given a 2-D PSD, we would integrate between the frequencies of $1 / \mathrm{mm}$ to $1 / \mu \mathrm{m}$ in order to assess the MSFR. Measurements may be required from more than one instrument in order to span a sufficiently wide frequency region. PSDs calculated from surface roughness measurements have shown excellent agreement with PSDs inferred from angle-resolved scattering data. ${ }^{4}$

\section{Metrology for EUVL Optics}

The bandwidths of the three specification categories given in Table 1, figure, MSFR, and HSFR, correspond approximately to the bandwidths measured by three types of instruments: full-aperture phase-shifting interferometry, phase-shifting interferometric microscopy, and atomic-force microscopy (AFM), respectively. Thus, power spectral densities can be assembled that cover an extremely wide spatial frequency band, i.e. $\mathrm{CA}^{-1}$ to $0.1 \mathrm{~nm}^{-1}$. It is outside of the scope of this summary to provide a comprehensive discussion of these types of measurements. However, the measurement of figure accuracy is an especially important issue, because of the need to measure absolute accuracy with respect to the optical design.

We have designed and built a phase-shifting diffraction interferometer (PSDI) for measuring the figure accuracy of EUVL mirror substrates. ${ }^{5}$ Errors in the reference have been minimized by using PSDI, where the fundamental process of diffraction is used to generate two arbitrarily perfect spherical wavefronts: one serves as the measurement wavefront and is incident on the mirror surface under test and the other serves as the reference wavefront. The calculated deviation from sphericity for reference waves generated with a diffracting aperture are of order $(10)^{-6}$ waves. Since they are generated independently, their relative amplitude and phase can be controlled, providing contrast adjustment and phase shifting capability. This concept has been implemented in several ways using lithographically generated apertures or single mode optical fibers.

\section{Conclusion}

The optics industry is currently attaining figure and finish values near those required for EUVL aspheres. The rate at which finishing performance is improving will enable a projection optics system to be assembled for meeting current EUVL program requirements.

\section{Notes and References}

\footnotetext{
${ }^{1}$ Auspices: This work was performed under the auspices of the U.S. Department of Energy by the Lawrence Livermore National Laboratory under Contract No. W-7405-ENG-48. Funding was provided by the Extreme Ultraviolet Limited Liability Corporation under a Cooperative Research and Development Agreement.

${ }^{2}$ For additional references and an expanded description of many topics mentioned in this summary, see: Taylor, J. S. et. al., "The fabrication and testing of optics for EUV lithography", in Emerging Lithographic Technologies II, Proc. SPIE vol. 3331 (1998) to be published.

${ }^{3}$ Kestner, R., "Precision asphere fabrication and metrology to tolerances $<1 \mathrm{~nm}$ rms", paper presented at the OSA Optical Fabrication and Testing Topical Meeting, Boston, May 1-3, 1996; note that this measured value represents the difference with respect to the vendor's interferometric reference, not a definitive statement of accuracy.

${ }^{4}$ Gullikson, E. M., "Nonspecular scattering for normal-incidence EUV optics", in Emerging Lithographic Technologies II, Proc. SPIE vol. 3331 (1998) to be published.

${ }^{5}$ Sommargren, G. E., "Phase shifting diffraction interferometry for measuring extreme ultraviolet optics", in Extreme Ultraviolet Lithography, Trends in Optics and Photonics (TOPS), vol. IV, G. D. Kubiak and D. R. Kania eds., Optical Society of America, pp. 108-112 (1996).
} 


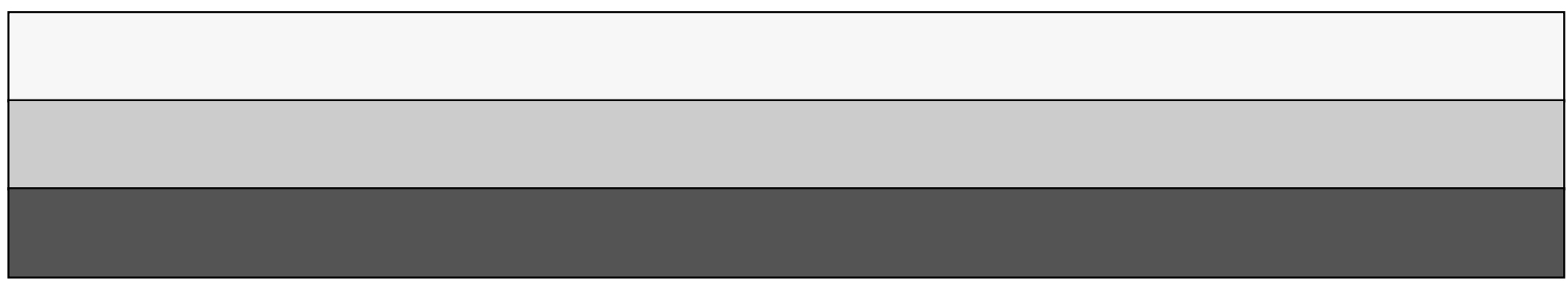

